\title{
PERBANDINGAN KEBOCORAN MIKRO PADA RESTORASI KOMPOSIT DENGAN PEMAKAIAN BONDING GENERASI KELIMA DAN BONDING GENERASI
}

\author{
KETUJUH
}

\author{
Karina Nabilla ${ }^{1}$, Defriman Djafri ${ }^{2}$, Dedi Sumantri ${ }^{1}$ \\ ${ }^{1}$ Faculty of Dentistry Andalas University \\ ${ }^{2}$ Departemen of Endodontics Faculty of Dentistry Andalas University
}

\begin{abstract}
Composite resin is the most frequently material used for restoring teeth but still failure cases are seen which leading to microleakage. Microleakage might be attributed to various factors, one of them is bonding agent. Various generations of bonding agents have been introduced to overcome the microleakage. The aim of this study was to evaluate the microleakage of composite restorations using the fifth and seventh bonding agent. Class I cavities $(3 X 2 X 2 \mathrm{~mm})$ were prepared on the occlusal surfaces of 32 human upper premolars. Teeth were classified into two groups according to the type of bonding agent used $(n=16)$. Group I: Fifth Generation of Bonding Agent-Adper Single Bond2. Group II: Seventh Generation of Bonding Agent-Single Bond Universal. All cavities were restored with Filtek Z250 XT composite resin, stored in sterile aquades water at $37^{0} \mathrm{C}$ for $24 \mathrm{~h}$. The root apices were sealed with sticky wax, and all the surfaces, except for $2 \mathrm{~mm}$ from the margins, were coated with nail varnish. The teeth were immersed in a $1 \%$ methylene blue dye solution for $24 \mathrm{~h}$, and then rinsed in running water, blot-dried and sectioned longitudinally through the center of restorations from the buccal to palatal surface. The sections were blindly assessed for microleakage of dye penetration by using a stereomicroscope. Data were collected and statistically analyzed by independent $t$ test. There was no significant difference $(p>0,05)$ between two groups. The conclusion is fifth generation of bonding agent revealed less leakage compared to the seventh generation even statistically there was no significant difference.
\end{abstract}

Keywords:Microleakage, fifth generation of bonding agent, seventh generation of bonding agent.

Affiliasi penulis : 1. Fakultas Kedokteran Gigi Universitas Andalas, 2. Fakultas Kesehatan Masyarakat Universitas Andalas

Korespondensi: Karina Nabilla, email: k.nabilla@rocketmail.com

Telp: 081270909888

\section{PENDAHULUAN}

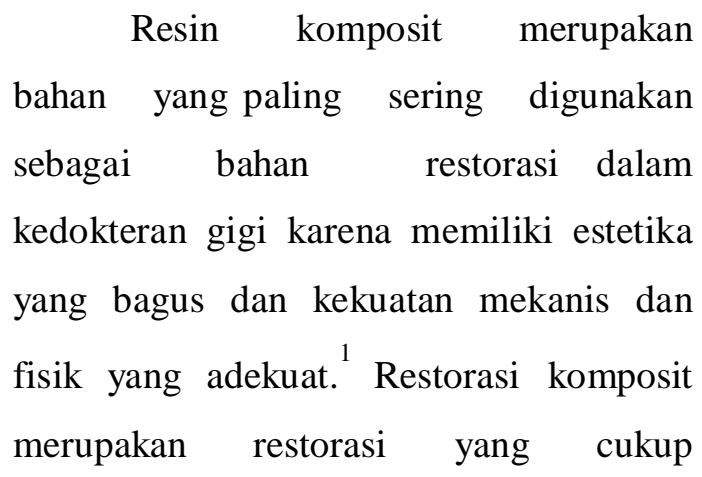

menguntungkan, namun kegagalan restorasi komposit dapat terjadi dan menyebabkan dibutuhkannya pergantian restorasi sehingga memakan waktu dan biaya yang lebih. Berdasarkan penelitian Da Rosa Rodolpho dkk, restorasi komposit yang dapat bertahan selama 5 tahun tanpa adanya kegagalan restorasi adalah hanya $1.55-2.2 \%$ dari keseluruhan total perawatan. Penyebab kegagalan restorasi tersebut salah satunya adalah kebocoran mikro.

Kebocoran mikro dapat 
didefinisikan sebagai celah mikroskopik yang terdapat diantara dinding kavitas dan bahan restorasi. ${ }^{3}$ Kebocoran mikro menimbulkan perubahan warna disekitar batas tepi suatu restorasi/marginal staining, karies sekunder, gigi sensitif, penyakit pulpa atau kematian pulpa yang berujung pada kegagalan suatu restorasi.

Faktor- faktor yang mempengaruhi terjadinya kebocoran mikro antara lain tipe substrat pada permukaan gigi, bentuk kavitas, configuration-factor/c-factor, teknik aplikasi bahan restorasi, dan jenis bahan restorasi dan bonding agent yang digunakan. ${ }^{5}$

Bonding agent merupakan bahan yang digunakan untuk melekatkan bahan restorasi pada permukaan enamel dan dentin, sehingga restorasi tersebut memiliki retensi terhadap permukaan gigi. Retensi didapatkan dari bahan bonding yang berpenetrasi terhadap permukaan enamel dan dentin dan bereaksi secara kimia sehingga membentuk micromechanical retention. ${ }^{6}$ Tujuan utama penggunaan bonding agent adalah untuk meningkatkan kekuatan perlekatan antara resin dan permukaan gigi, meningkatkan retensi bahan restorasi, dan mengurangi terjadinya kebocoran mikro antara permukaan resin dan dentin. Bonding agent tidak hanya digunakan untuk restorasi komposit, tetapi juga dapat digunakan sebagai bahan bonding orthodontic bracket, periodontal splint, pit dan fissure sealant, dan lain-lain ${ }^{6 .}$

$$
\text { Bonding agent memiliki } 3
$$
komponen, yaitu etsa, primer, dan adhesive. Etsa adalah bahan kimia yang bersifat asam yang berfungsi untuk menghilangkan permukaan mineral gigi dan membentuk micropores yang membuat permukaan enamel menjadi kasar sehingga resin komposit dapat berikatan dengan permukaan gigi dan membentuk resin tag. Etsa membentuk resin tag dari proses demineralisasi ion kalsium pada permukaan superfisial enamel, sehingga membuat permukaan menjadi lebih reaktif terhadap bahan resin. Etsa yang sering digunakan adalah asam fosforik 37\%. Primer pada bonding agent mengandung bahan monomer yang dilarutkan dalam air, alkohol dan aseton yang memiliki komponen hidrofobik (gugus metakrilat) dan hidrofilik (gugus hydroxyl atau carboxyl). Primer berfungsi untuk memudahkan perlekatan resin komposit pada permukaan gigi. Adhesive pada bonding agent memiliki komponen yang sama dengan primer, memiliki peranan penting dalam menghasilkan ikatan antara dentin dan resin komposit.

Berdasarkan perkembangannya, bonding agent dibagi menjadi 8 tipe : bonding generasi bonding agent dibagi menjadi 8 tipe : bonding generasi 
pertama, bonding generasi kedua, bonding generasi ketiga, bonding generasi keempat, bonding generasi kelima, bonding generasi keenam, bonding generasi ketujuh dan bonding generasi kedelapan. Berdasarkan tahapan prosedur kerjanya, bonding agent dibagi menjadi 3 tipe : 3 steps bonding agent (aplikasi etsa, primer, dan adhesive secara simultan dan terpisah), 2 steps bonding agent (etsa dan primer/primer dan adhesive berada pada satu kemasan, sementara etsa/adhesive diaplikasikan secara terpisah) dan 1 step bonding agent (etsa, primer dan adhesive berada dalam satu kemasan). Bonding agent juga diklasifikasi menurut sistem etsanya menjadi 2 tipe yaitu total-etch system/rinse technique dan self-etch system/non-rinse technique.

Jenis bonding yang saat ini digunakan adalah bonding total-etch dan self-etch. Perbedaan dari kedua jenis bonding ini adalah prosedur etsanya. Bonding total-etch memiliki prosedur etsa yang terpisah dari komponen primer dan adhesivenya sementara bonding jenis self-etch memiliki komponen monomer asam dalam primernya sehingga prosedur etsa tidak dilakukan. Bonding generasi keempat dan kelima termasuk bonding jenis total-etch ini, sementara yang termasuk bonding jenis self-etch adalah bonding generasi keenam, ketujuh, dan kedelapan. Jenis bonding yang saat ini paling banyak digunakan dan mudah didapatkan adalah bonding generasi kelima dan ketujuh.

Beberapa penelitian telah dilakukan untuk menilai kebocoran mikro yang terjadi pada suatu restorasi komposit. Diansari dkk. melakukan penelitian melihat kebocoran mikro dengan pemakaian bonding total-etch dan self-etch dengan jarak penyinaran yang berbeda. Hasil dari penelitian tersebut menunjukkan terdapat perbedaan signifikan pada nilai kebocoran mikro dengan jarak $2 \mathrm{~mm}$ dan bonding total-etch memiliki nilai kebocoran mikro lebih rendah dibandingkan bonding selfetch. ${ }^{9}$ El Slayed dkk. melakukan penelitian tentang perbandingan kebocoran mikro yang terjadi pada penggunaan bonding agent tipe total-etch dan self-etch. Hasil penelitian menunjukkan bonding agent tipe total-etch memiliki nilai kebocoran mikro yang lebih kecil secara signifikan dari bonding agent tipe self-etch. ${ }^{10}$

Penelitian yang sama juga dilakukan Tabari dkk. terhadap gigi anterior desidui yang diberi restorasi komposit. Tidak terdapat perbedaan signifikan antara nilai kebocoran mikro yang dihasilkan oleh pemakaian bonding agent tipe total-etch dan self-etch. ${ }^{11}$ Rosales- Leal dkk. melakukan penelitian untuk melihat perbedaan kebocoran mikro yang terjadi pada restorasi komposit dengan penggunaan bonding generasi 
keempat,kelima,keenam dan ketujuh. Penelitian tersebut juga melihat pengaruh proses thermocycling terhadap kebocoran mikro yang terjadi. Hasil penelitian menunjukkan proses thermocycling tidak mempengaruhi nilai kebocoran mikro secara signifikan dan nilai rata-rata kebocoran mikro tertinggi terletak pada grup dengan jenis bonding yang digunakan adalah bonding generasi keempat dan bonding generasi ketujuh. ${ }^{12}$ Berdasarkan uraian diatas, perlu dilakukan penelitian untuk membandingkan kebocoran dilakukan penelitian untuk membandingkan kebocoran mikro pada restorasi komposit dengan pemakaian bonding generasi kelima dan bonding generasi ketujuh.

\section{METODE}

Jenis penelitian yang digunakan adalah experimental dengan desain penelitian post-test design dengan jumlah sampel sebanyak 32 gigi. Sampel dipilih berdasarkan kriteria inklusi lalu dipreparasi dengan bentuk kavitas klas I (3X2X2 mm). Gigi tersebut kemudian dikelompokkan menjadi 2 grup sesuai dengan jenis bonding yang digunakan $(\mathrm{n}=16)$. Grup I : Bonding generasi kelimaAdper Single Bond2. Grup II: Bonding generasi ketujuh-Single Bond Universal. Seluruh kavitas kemudian di restorasi dengan resin komposit Filtek Z250 XT dan direndam dalam aquades steril dengan suhu $37^{\circ} \mathrm{C}$ selama 24 jam. Apeks pada akar ditutup dengan sticky wax, dan seluruh permukaan gigi dan restorasi diberi cat kuku kecuali $2 \mathrm{~mm}$ dari tepi restorasi. Sampel direndam dengan larutan methylene blue 1\% selama 24 jam, lalu dibilas dengan air mengalir, dikeringkan dan dipotong longitudinal dengan arah buko-palatal.

Penilaian kebocoran mikro dilihat dari penetrasi warna yang dievaluasi menggunakan stereomicroscope. Persentase kedalaman penetrasi warna dihitung berdasarkan rumus $\mathrm{A} / \mathrm{B} \quad \mathrm{X}$ $100 \%$ dimana $A=$ kedalaman penetrasi warna dan $\mathrm{B}=$ kedalaman restorasi. Hasil tersebut kemudian dikelompokkan mejadi 3 kelompok skor, dengan skor $1=0.1$ $33.3 \%$, skor $2=33.4-66.6 \%$, skor $3=66.7-100 \%$.

\section{HASIL}

Gambar 1. Distribusi Frekuensi Skor Kebocoran Mikro

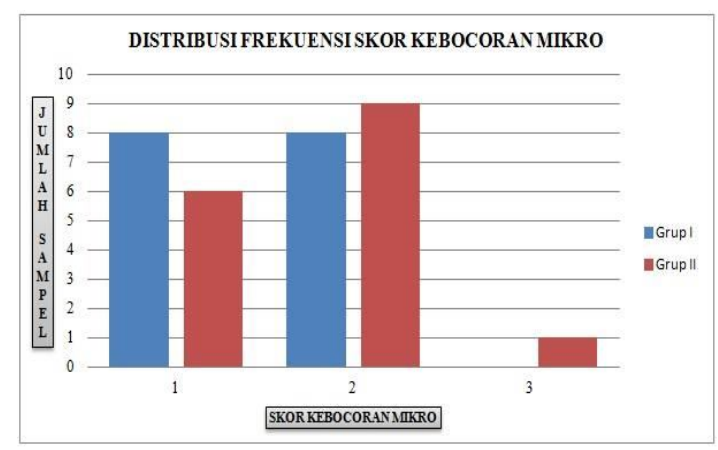

Grup I merupakan kelompok sampel dengan menggunakan bonding generasi kelima dan grup II merupakan kelompok sampel yang menggunakan 
bonding generasi ketujuh. Berdasarkan

Gambar 1 diketahui bahwa distribusi skor kebocoran mikro pada grup I diketahui sebanyak 8 sampel memiliki kebocoran mikro dengan skor 1,8 sampel dengan skor 2 dan tidak terdapat sampel dengan skor 3. Distribusi frekuensi skor kebocoran mikro pada grup II diketahui terdapat 6 sampel dengan skor 1, 9 sampel dengan skor 2, dan 1 sampel dengan skor 3. Dapat dihitung bahwa total skor pada grup I adalah 24 dan total skor untuk grup II adalah 27. Grup I memiliki total skor kebocoran mikro yang lebih rendah dibandingkan grup II.

Hasil analisis statistik menggunakan uji Chi- Square didapatkan $p$ value $=0.511$. Dapat diartikan bahwa tidak terdapat perbedaan signifikan ( $>>0.05)$ antara kebocoran mikro pada restorasi komposit dengan menggunakan bonding generasi kelima dan bonding generasi ketujuh.

\section{PEMBAHASAN}

Grup I memperlihatkan jumlah yang sama pada skor 1 dan skor 2. Hal ini memperlihatkan bahwa kemampuan bonding generasi kelima dinilai cukup baik dalam menghasilkan marginal seal. Hal ini disebabkan karena kemampuan etsa pada bonding generasi kelima yang menghasilkan micropores yang adekuat pada permukaan enamel sehingga penetrasi larutan warna yang terjadi tidak melebih batas 2/3 kedalaman restorasi.

Berbeda dengan grup I, grup II memperlihatkan hasil yang lebih bervariasi. Grup II menunjukkan skor terbanyak yaitu skor 2 dan terdapat gigi dengan skor kebocoran mikronya 3 . Bonding generasi ketujuh memiliki asam primer sebagai pengganti etsa tetapi asam primer tersebut memiliki $\mathrm{pH}$ yang lebih ringan dibandingkan etsa sehingga micropores yang dibentuk tidak sebaik etsa, sehingga terlihat pada grup II gigi dengan skor kebocoran mikro 2 lebih tinggi dibandingkan skor 1 . Posisi skor 2 berada diantara ditengah-tengah antara permukaan oklusal dan mendekati permukaan dentin gigi, sehingga terdapat perbedaan struktur pada dinding kavitas dimana komponen anorganiknya berkurang dan komposisi airnya pun semakin bertambah dibandingkan permukaan oklusal. Keadaan ini dianggap menguntungkan bagi bonding generasi ketujuh yang memiliki keunggulan dalam menghasilkan ikatan dentin yang lebih baik. Komponen HEMA yang terdapat dalam bonding generasi ketujuh memiliki kemampuan penetrasi pada restorasi resin komposit dengan menggunakan bonding generasi kelima dan restorasi komposit dengan menggunakan bonding generasi ketujuh. 2. Tidak terdapat perbedaan yang signifikan antara kebocoran mikro pada restorasi resin 
komposit dengan menggunakan bonding generasi kelima dan restorasi komposit dengan menggunakan bonding generasi ketujuh. kelima dan bonding generasi ketujuh dapat disimpulkan: 1. Total skor kebocoran mikro pada restorasi komposit dengan 2. Tidak terdapat perbedaan yang signifikan antara kebocoran mikro pada restorasi resin komposit dengan menggunakan bonding generasi kelima dan restorasi komposit dengan menggunakan bonding generasi ketujuh kedalam dentin yang tinggi dan juga berikatan dengan baik pada substrat karena sifat hidrofiliknya mampu menghasilkan kelembaban permukaan yang stabil. HEMA juga dapat menghasilkan ikatan hidrogen didalam dentin yang terdemineralisasi dan membentuk mechanical interlocking pada substrat setelah proses polimerisasinya. ${ }^{10,14}$ Adanya ikatan yang kuat ini mencegah larutan pewarna berpenetrasi lebih dalam pada sampel grup II sehingga terlihat

\section{KESIMPULAN}

Dari hasil penelitian mengenai kebocoran mikro pada restorasi komposit dengan menggunakan bonding generasi kelima dan bonding generasi ketujuh dapat disimpulkan :

1. Total skor kebocoran mikro pada restorasi komposit dengan

2. Tidak terdapat perbedaan yang signifikan antara kebocoran mikro pada restorasi resin komposit dengan menggunakan bonding generasi kelima dan restorasi komposit dengan menggunakan bonding generasi ketujuh.

\section{KEPUSTAKAAN}

1. Turicer D, Celik C, Cehreli SB, Arhun N.Comparison of microelakage of a multi-mode adhesive system with contemporary adhesives in class II resin restorations. J Ad ST. 2014;28(13):1288-1297.

2. Demarco FF, Correa MB, Cenci MS, Moraes RR, Opdam NJM. Longevity of posterior composite restorations: not only a matter of materials. J Dental Material Elsevier. 2012;28:87-101.

3. Anusavice KJ. Phillips' science of dental materials. $11^{\text {th }}$ ed. St. Louis: Elsevier;2003.381.

4. Fabianelli A, Pollington S, Davidson CL, Cagidiaco MC, Goracci C. The relevance of microleakage studies. Int Dent SA. 2007;9(3):64-74.

5. Nunes MCP, Franco EB, Pereira JC. Marginal microleakage: critical analysis of methodology. Salusvita Bauru. 2005;24(3):487-502.

6. Powers JM, Wataha JC. Dental Materials Properties and Manipulation. $\quad 9^{\text {th }}$ ed. Missouri:Mosby Elsevier; 2008. $85 \mathrm{p}$.

7. El Slayed HY, Abdalla AI, Shalby ME. Marginal microleakage of composite resin restorations bonded by 
desensitizing one step self etch adhesive. Tanta Dent J. 2014;11:180-188.

8. Kakar S, Goswami M, Kanase A. Dentin bonding agents I: complete classification-a review. World J Dent. Oct-Dec 2011;2(4):367-370.

9. Diansari V, Eriwati YK, Indriani DJ. Kebocoran mikro pada restorasi komposit resin dengan sistem total-etch dan selfetch pada berbagai jarak penyinaran. Indonesian Journal Of Dentistry. 2008;15(2):121-130.

10. El Slayed HY, Abdalla AI, Shalby ME. Marginal microleakage of composite resin restorations bonded by desensitizing one step self etch adhesive. Tanta Dent J. 2014;11:180-188.

11. Tabari $\mathrm{M}$ et al. Comparative evaluation of microleakage of composite restorations using fifth and seventh generations of adhesive systems. Caspian J Dent Res. 2014;3:14-19.

12. Rosales-Leal JI. Microleakage of class V composite restorations placed with etch-and- rinse and self-etching adhesives before and after thermocycling. J Adhes Dent. 2007;9:255-259.

13. Al-Homaidhi M, Al-Dlaigan YH. Microleakage of a pit and fissure sealant used with two brands of self-etching adhesives:an in vitro study. J Int Oral Health. 2016;8(3):332-337.

14. Somani R, Jaidka S, Arora S. Comparative evaluation of microleakage of newer generation dentin bonding agents: an in vitro study. J Dent Res. 2016;27:87. 